Este artigo toca num dilema crucial da educação nos dias de hoje - a violência -, problematizando qual seria o papel da escola - um dos últimos redutos do conviver, nesta sociedade marcada pelo individualismo - na produção da violência ou na tentativa de pacificação das relações humanas. A autora destaca que a racionalidade, na qual a educação tenta se apoiar cada vez mais para negar-se como profissão impossível, fracassa em governar as almas e as relações subjetivas, não podendo prever inteiramente o destino humano, entregue sempre ao acaso e aos encontros. Educacâa; violência; escola; individualismo; racionalidade; encontro

TO EDUCATE, AN IMPOSSIBLE JOB. CONTEMPORARY DILEMMAS

This article touches on a crucial problem regarding education nowadays violence. It questions what the role of the scbool - one of the last bavens of community life -, would be, in a society where individualism reigns - either by producing violence or by attempting to bring peace into people's relations. The autbor remarks that rationality, on which education tries increasingly to rest as a way of denying itself as an impossible profession, fails to govern the soul and the subjective relations. It cannot entirely forecast buman destiny, which is always vulnerable to chance and encounters. Education violence, (sbcool) (scbool); individualtsm; rationality; encounter

\section{EDUCAR, \\ UMA PROFISSÃO IMPOSSÍVEL - DILEMAS ATUAIS}

Mireille Cifali

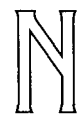

a educação, confrontamos inelutavelmente com dilemas. Acreditamos ter resolvido uma dificuldade, e a solução encontrada cria efeitos não previstos. A violência é combatida, mas uma radical não-violência revela-se por certos aspectos nociva. Prega-se o amor, mas este, às vezes, sufoca a vida. O respeito está na ordem do dia, mas ele pode acarretar paralisias na relação com o outro. O abuso de poder de um adulto é denunciado, designa-se a vítima que se torna a criança, e se o encerra num estatuto em que suas forças vivas são engolidas. Muitos profissionais refletem a respeito, querem "fazer bem", e não assumem mais o mal inelutável que decorre de alguns de seus gestos. Perseguimos uma certa racionalidade como garantia da justeza de nossos atos, esta racionalidade pode se tornar loucura. E, mesmo se conhecemos certos males, temos dificuldade em preveni-los. Um trabalho de Sísifo caracteriza essas profissões "impossíveis" (Cifali, Enriquez \& Cornut, 1987), nas quais estamos sempre certos, de alguma maneira, de fracassar. Talvez devamos então, principalmente, aceitar que os dilemas fazem parte de toda profissão, e é vão procurar coerência e não-contradição.

- Profa $\mathrm{dr}^{\mathrm{a}}$ da Faculdade de Psicologia e Ciências da Educação da Universidade de Genebra - Suiça.

च Tradução: Renata Petri 


\section{NO LIMITE DA VIOLÊNCIA}

Nos dias de hoje, ganhamos nossa individualidade (Taylor, 1994), sentimo-nos ser sujeitos com direitos e, sobretudo, temos a necessidade de forjar nossa própria vida. E então vemos despontar um problema crucial, como conseqüência dessas individualidades às vezes tão imbuídas de si mesmas: viver com o outro, nosso vizinho. Se este individualismo vem se acentuar, o laço entre os indivíduos corre o risco de se atenuar mais ainda; as relações de proximidade perderão seu brilho, e os direitos de cada um serão regulados pelo jurídico. Esta tendência tem certamente seus benefícios: cada um será livre para viver por si, pode se esperar menos confrontações com o outro, menos conflitos. Evitaremos assim talvez as tensões do conviver individualizando-nos cada vez mais, protegendo cada um de nós, mas perderemos a riqueza de nossa relação com o outro, uma vez que até aqui não houve vida sem coletividade, não houve trabalho sem colaboração, nem aprendizagem sem emulação dos outros.

A escola é uma das últimas instituições que confrontam o sujeito com o viver junto. Se a família, desinstitucionalizada, tornou-se um negócio privado, como o constatam alguns historiadores, a escola poderia igualmente tornar-se privada. A crise da autoridade afetando a escola por sua vez, a dificuldade em trabalhar com um grupo, os processos de desidentificação nos levarão na direção de uma individualização dos procedimentos de aprendizagem e uma evitação do conviver. Se a classe desaparece como espaço comum, então triunfará este individualismo, que se teme possa tornar difícil toda relação com o outro, e nos faça perder uma constante do humano: aquela na qual "eu" não existe sem o outro. Entraremos num reino da auto-suficiência, enquanto a intersubjetividade foi até o presente o fundamento de nossa subjetividade.

Um dos desafios futuros será resistir a uma tal evolução e articular essas individualidades à necessidade de viver, criar e ser responsável em conjunto. Poderíamos assim contar com a liberação da potência do sujeito e conjuntamente com sua aceitação de ser, no entanto, "um entre os outros"2. A partir de uma tal tomada de posição filosófica, decorrerão as finalidades da escola, as condições do exercício da profissão de ensinar e da experiência de aprender. Falaremos ainda amanhã de liberdade, de autonomia, de capacidade de pensar, de espírito crítico, de tensão entre o mesmo e o diferente? Ou estes termos não terão mais sentido, pois o humano será feliz na sua suficiência, nessa bolha protetora e segura que se terá construído para protegê-lo do outro?

Se a sociedade evolui no sentido de um regime social no qual cada cidadão é chamado a exercer sua virtude política, em que o conviver é possível, cada indivíduo sendo responsável 
por si mesmo e pelos outros, então a escola será uma "escola do sujeito" (Touraine, 1997) e se manterá como espaço comum. Senão, ela desaparecerá, dando lugar a procedimentos adaptados a cada um, mas também a uma normalização dos comportamentos, uma conformização, que seria, por exemplo, medicamentosa; a sociedade escorregará na direção de um totalitarismo inédito, que não engendrará mais uma educação e uma repressão de massa, mas um controle das intimidades baseado numa ausência de relação recíproca, e podemos nos perguntar o que será feito do amor.

\section{PACIFICADO}

A educação criou um ponto de honra, de pacificar as relações humanas, isto foi um de seus credos. Os historiadores mostram que efetivamente a relação com a violência entre os civis e no cotidiano evoluiu (Lagrange, 1995). A maioria de nós tem horror à violência em atos, não sabemos mais nos defender, o corpo-a-corpo dá medo. Sabemos também que banalizamos a violência na imagem, e que a pacificação vai junto com as explosões de violência: quanto mais alguns se pacificam, mais outros têm somente a violência como recurso para existir (Cifali, 1998). Não falo da violência estatizada, aquela entre as nações, mas da violência no cotidiano das relações. Esta foi a esperança de uma pedagogia psicanalítica: impedir o advento da guerra. Hoje, perdemos nossas ilusões, a educação se tornou um projeto dos mais realistas.

Se a escola se mantém como um lugar em que as diferenças se confrontam, se a medicina não encontrou uma pilula da obediência e uma outra para tratar a agressividade, se alguns continuam a ser excluídos, o controle entre as crianças continuará no futuro a es- tar na ordem do dia. É, aliás, um de nossos sofrimentos profissionais atuais: a confrontação à insubmissão, à violência passiva e ativa, à ineficácia das punições e ameaças habituais. O adulto pode até chegar a sonhar em acalmar a criança, dando-lhe uma camisade-força química, que a manterá tranqüila, não amorfa demais para que ela seja ainda capaz de pensar. A medicina nos dará os meios, a ética impedirá, talvez, que se resolva assim o problema. Mas a vontade de trabalhar com alguém pacificado, regularizado, conforme, exatamente espelho de nós mesmos, corre o risco de ser tenaz.

Como não retornaremos a uma pedagogia repressiva, na qual se alternam humilhação e ternura, inventaremos redes de vigilância, meios de controlar a intimidade e os pensamentos, influências nos comportamentos (Enriquez, 1997). Acreditamos ter conquistado um espaço de intimidade que escaparia ao controle social, mas nos mantivemos numa ilusão. O controle das intimidades nunca foi tão forte, a invasão na vida privada nunca foi tão longe. A aliança entre a medicina, a telemática e o jurídico poderia muito bem ter o resultado esperado: uma vigilância das condutas, uma normatividade dos comportamentos e uma obediência às regras editadas. Estaríamos numa sociedade que encontrou um meio de controlar os pensamentos e os comportamentos. E um adulto não terá mais de se preocupar com a disciplina: é o sonho totalitário que está em cada um de nós.

Se tivermos discernimento, confrontaremos sempre as questôes de ontem e de hoje: como derrotar nossas agressividades, como permitir que cada humano regule seus atos, ultrapasse seu egoísmo, guie seu agir segundo um princípio de responsabilidade, trabalhe pelo bem comum, e não somente pelo 
seu bem, renuncie a certos prazeres, uma vez que são destrutivos para o outro, exista sem precisar desvalorizar o outro e mesmo rejeitá-lo. Hoje a questão da referência à lei é crucial. No domínio da educação, como em outros domínios, nos esforçamos a fim de passar da moral para a ética, da obediência à responsabilidade, da submissão ao espaço para uma discussão crítica, da aplicação de uma lei à colocação em ato de uma lei que, às vezes, na singularidade de uma situação, deva ser transgredida para conservar seu espírito, e não sua letra; tentamos não nos esquivar quando é preciso escolher entre um respeito à regra ou à pessoa ${ }^{3}$.

\section{ENCONTRO}

Vemos atualmente se desenhar uma corrente que considera a criança como uma minoria e que tenta diante desse escândalo outorgar-lhe direitos. Na corrente de nosso século XX, compreendemos como uma criança se torna vítima de violência, de abuso, de maus-tratos, de exploração, apesar dos discursos gerais que se sucedem (Gavarini \& Petitot, 1998). Estes abusos repetidos, no lugar em que deveríamos estar obrigados diante deles, lá onde reside nossa responsabilidade fundamental, são denunciados, e é melhor assim. Procura-se proteger a criança das conseqüências às vezes nocivas de sua dependência. Mas, em se fazendo isso - e este é o debate atual acerca dos direitos da criança -, estamos lhe dando direitos, instituindo-a como responsável e autônoma antes da hora, e quebrando sua legítima dependência (Eliacheff, 1996). Estamos, por causa do abuso, pondo em perigo uma dependência fundamental, a de um humano em relação a outro humano, e estamos instalando relações nas quais o intersubjetivo re- 
sume-se no afrontamento de um direito contra um outro. Pode-se imaginar que, se essa tendência prossegue, as crianças logo serão clientes que será preciso servir, que poderão nos denunciar se não gostarem de alguma coisa, que usarão os adultos como objetos e poderão jogá-los fora se não servirem mais. De fato, teríamos somente invertido a cena; serão as crianças que se tornarão tirânicas, suficientes, cruéis, destruidoras, com aqueles que se aproximarem, e isso com a força de estarem confortáveis em seus direitos.

Toda inversão é nociva. É necessário que os adultos, tanto pais como professores, assumam suas responsabilidades e suas obrigações, e não utilizem a fraqueza da criança de maneira ruim. Mas seria dramático se o poder dado às crianças sobre os adultos levasse a isso. Entre estas duas culturas, iríamos na direção de um combate, um face-a-face de violência. Como respeitar a dependência, mobilizar a responsabilidade do adulto e trabalhar sobre os abusos? Tal é a perspectiva, ou seja, ao mesmo tempo permitir à criança que sua palavra seja escutada, mas que ela não seja mais poderosa que a dos outros.

\section{CONFRONTADAS}

\section{AO MAL}

Podemos retornar a nossa posição de profissionais, uma vez que aqueles que estão sofrendo com aquilo que os fez sofrer vêm tentar integrar nas suas vidas o que foi insuportável. Muitas questões se põem. Como ajudar a vítima a não se identificar com seu trauma, como, enquanto profissional, não repetir o trauma já sofrido? Nossa sociedade deu legitimamente existência àqueles que sofreram o mal. Mas transformá-los em vítimas pode se mostrar nocivo.
Muitas críticas sobre o trabalho dos psicólogos mostram que a vitimização dos indivíduos é uma armadilha, rentável para esses profissionais. O humano não se reduz a seu estado de vítima, afirma, com veemência, Alain Badiou (1993), quando fala do mal e da ética. Designar alguém pelo seu trauma vem novamente impedir de integrá-lo numa evolução e o impele a fundar sua identidade sobre ele. $O$ discurso psicológico não é sem ressonância sobre o social e sobre a evolução do sujeito, no seu desejo de uma segurança a qualquer preço, na sua queixa contínua em face do sofrimento encontrado na vida. Como dizer a identidade sem bloqueá-la? Como trabalhar para descentrar o sujeito doloroso de si mesmo?

A clínica daqueles que sofreram o mal é o terreno dos terapeutas. A reparação lhes compete. O trabalho de clínico se mantém na borda deste enigma: como este acontecimento - o mal sofrido - pode não se repetir, como esse sofrimento pode não se incrustar, como a vida pode integrá-lo, onde estão as fontes, as forças de vida de uma pessoa, como de vítima ela pode não se tornar carrasco? É nosso papel, uma vez o mal feito, mas este trabalho é de prevenção, pois trabalhamos para que o sofrimento não recaia sobre outros, que a vítima não engendre outras vítimas. Às vezes, no entanto, vemos essas profissões denunciar o mal e por sua ação repetir o mal sofrido, usar o outro mais uma vez para seu narcisismo e seu bom direito. Assim acontece às vezes com o mau trato sexual, e com a maneira com que certos psicólogos e assistentes sociais fazem uso disso no debate social e na caça ao monstro ${ }^{4}$.

A partir dessa clínica da vítima, podem-se tomar posições sociais, que correm o risco de desvios. Somos as testemunhas do sofrimento de um des- 
tino quebrado pela violência, do intolerável de uma violência atualizada sobre uma criança, uma mulher ou um homem, da paixão destruidora de um casal, da agressão selvagem de uma pessoa velha, e podemos medir as conseqüências enquanto clínicos. Poderíamos optar por uma posição extrema que consistiria em sustentar que nossa profissão intervém uma vez o mal feito, que não somos responsáveis pela sociedade, pelos erros humanos e pelas condições que causam o mal. Nossa profissão é ligada ao mal, e nossa existência social também. Poderíamos ficar nisso, esperando até mesmo que o mal não se atenue, pois isto nos lançaria na impossibilidade de exercer.

O discurso é clínico, não podemos mantê-lo. Em nome das vítimas, nos associamos aos movimentos que querem que o mal cesse, que a violência se atenue, que o outro se torne menos ameaçador. Saímos de nossa reserva. Saberemos, no entanto, compreender que nossa posição não pode resolver sozinha o problema da violência, e que nós contribuímos, como outras profissões, indiretamente, para fabricar a desconfiança? Eu subscrevo a posição de Antoine Garapon e Denis Salas (1996), que sustentam que o problema do mal não se revolve unicamente com o discurso psicológico. Enquanto profissionais, temos de nos interrogar sobre nossa participação nessa vitimização e no fato de que, cada vez mais, nos tomamos a nós mesmos como vítimas detentoras de direitos. A vida é um risco, feita de encontros bons e ruins, de sofrimento, no qual devemos em segui$\mathrm{da}$ encontrar forças e fontes para que não seja tão destrutivo. Nossas profissões consistem minimamente em não acrescentar destrutividade àquela inerente à vida, em permitir que se tirem dos inevitáveis acidentes negativos forças de vida, e não forças de morte. So- mos convidados a fazer uma reflexão sobre a ética de nossos gestos, e a sermos atentos aos que estão em extrema fragilidade social.

\section{RESPEITO INIBIDOR}

Nas nossas profissões, chegamos a um tal respeito pelo outro, que não se ousa mais quase nem tocá-lo. "Respeite-me" transforma-se em "aceite-me como eu sou", "não me peça nada", "não me empurre", "deixe-me onde estou com aqueles que se parecem comigo", "ame-me, mas como eu sou". "Você me deve respeito" parece finalmente significar: "Eu sou suficiente, e meu encontro com você não mudará nada do que eu sou". Se lhe devemos respeito, podemos então exigir dele alguma coisa, impor-lhe o que ele não quer à primeira vista? Se sentimos como violência tudo aquilo que não entra no nosso mundo, e vice-versa, então é o fim do encontro. Mas no fundo o que permite crescer, aprender? É o fato de ser empurrado, desencaminhado, puxado para fora de si mesmo, ser seduzido pelo que não se é? Ora, um respeito tomado ao pé da letra nos interdita empurrar este outro, de querer outra coisa dele; tem-se em conta seu "eu não quero" emitido primeiramente porque ele tem medo, pois o esforço demanda a saída de sua tranqüilidade. Desta forma, os gestos do encontro, os dispositivos propostos podem ser sentidos como violência.

O que é um encontro? Ele acontece entre dois seres, sem poder ser programado. Ele transforma, como num verdadeiro diálogo que nos deixa outros depois que nossas palavras tenham sido trocadas (Gadamer, 1995). Todos os profissionais podem ser seres de encontro. Muitos biógrafos relatam esses encontros sem os quais não teríamos nos tornado o que somos: Camus 
(1994) e seu professor, por exemplo. Temos uma dívida a honrar, não a dívida impagável, mas a dívida em relação a alguns outros. Pode-se desejar a cada um na sua vida a possibilidade de ter encontros. Os adolescentes que voltaram de suas derivas o fizeram freqüentemente porque alguém esteve lá, não os deixando onde estavam, tendo confiança neles, empurrando-os, chacoalhando-os. Não é teorizável nem racionável. Isso pertence ao que escapa, e deveria escapar a toda programação. Estamos lá e alguma coisa irrompe. A presença do outro não nos deixa tranqüilos. Ele nos disse: "Você poderá", enquanto tudo enunciava o contrário. Esse encontro pertence ao humano; desde a noite dos tempos, faz-se a narrativa; amanhã ele deverá sempre poder ter lugar. Estamos postos, no entanto, num enigma. Quais particularidades psíquicas ou quais circunstâncias permitem tomar tal ou qual elemento a fim de mobilizá-lo para sua própria vida? Se estruturas exteriores dadas são indispensáveis para que um acontecimento advenha, em seguida é preciso que outra coisa aconteça para que esta estrutura desempenhe a função de uma possivel passagem.

Tocamos aqui na oposição das hipóteses entre determinismo sociológico e poética humana. Enquanto profissionais, se não devemos negar a influência dos determinismos psíquicos e sociais, temos também de contar com a exceção que sela justamente o encontro. Importa que tenha estruturas, técnicas, possibilidades, para que um humano possa aí encontrar o que será uma parte de sua vida. As ocasiões nos permitem nos enxertar e descobrir o que vai nos mobilizar. Um outro, tornamo-lo possível não respeitando o que somos, nossos hábitos, nosso ensimesmamento. Isto se chama cultura, sistema simbólico, do qual cada um precisa e que não é constituído de outra coisa senão materialidade, mas também de imaterialidade. Certamente existem encontros destrutivos. Um humano pode ser nocivo para outro. Em nome dessa nocividade, poderíamos proteger cada um e impedir que a partir de então os encontros tenham lugar, tomados na armadilha de um pensamento que, sempre partindo do nocivo, quer extirpar o mal.

\section{CONSEQÜÊNCIAS}

Falando do terapeuta, Winnicott (1988) escrevia que acontecia de ele referenciar-se na crueldade que é forçosamente a sua própria, a fim de não atualizá-la sobre um outro. Isto retorna à sua responsabilidade de profissional. Eu diria mesmo para toda profissão do humano, quer se trate de curar, de instruir ou de educar. Nossa crueldade deve ser trabalhada, tomando consciência de que ela pode se atualizar tanto mais facilmente quanto fomos fragilizados, que não compreendemos mais que um outro não é mais nosso espelho, e nos surpreende com seus atos. Só a trabalharemos se chegarmos a falar do que se passa conosco, quando somos tomados pelo outro, que nossas defesas habituais não funcionam mais. Freqüentemente temos vergonha de nossas reações excessivas, no entanto, não podemos ser diferentes. Ter vergonha é se esconder, se calar. Ora, se não falamos, não podemos pensar o que acontece, nem nos distanciar, nem tomar a medida.

Cada profissão tem sua ideologia defensiva, na qual se constrói uma maneira de se defender do medo. O medo de nossa fraqueza, de falar de nossas dificuldades, pertence a este registro. Isto ultrapassa um indivíduo. O medo estrutura as profissões. Uma lei do silêncio atravessa-o nos lugares de sua 
fragilidade, lá onde para alguns existe perigo de morte e, para outros, perigo psíquico. Não se brinca nem com o medo, nem com os sistemas de defesa postos em ação; não se ridiculariza, mas não se deixa tampouco funcionar em silêncio. Existem sistemas de defesa que cumprem seu ofício, mas que obstaculizam, porque eles mobilizam nossa energia, reduzem o campo de nossa ação e de nosso pensamento. Tanto o medo como a angústia podem ser tratados diferentemente, com um mínimo custo psíquico, uma maior fluidez e inventividade. É aí que a palavra e a compreensão podem substituir certas defesas. Mantendo o silêncio, acaba-se morrendo de solidão, e pode-se permanecer cego quanto ao nosso pior.

\section{OBRIGADO A SER BOM}

Gostariamos hoje que o profissional fosse consciente de seus atos e refletisse sobre eles. Pensamos que assim poderemos encontrar o gesto "justo". Refletir para sair da ignorância ou dos preconceitos; sair de si para pensar a relação com o outro: tal seria a responsabilidade do autor para que seus gestos não fossem nocivos ou o fossem o menos possivel; ideal de um humano reflexivo, distanciando-se de certos a priori revelando uma psicologia ou uma sociologia inocente, ideal do pensamento ou do ato pensado. Não posso afirmar que este ideal de homem e de mulher reflexivos não seja aquele a que eu gostaria que cada um tendesse. Mas não contribuímos para a ilusão de que o homem que pensa é necessariamente bom, racional, e não destruidor? Por outro lado, uma vez que eu lido com seres que pensam seus atos, que têm consciência de suas responsabilidades, da vulnerabilidade do outro, eles querem - e é legítimo - estar no bem, no bom. Não suportam então serem "maus". 
Por um lado, certos professores provocam - quase inconscientemente, tão certos estão de seus atos - catástrofes, bloqueios, recusa de aprender, humilhação, rejeição de um outro. Eles também não têm a impressão de serem destruidores. Se o outro se destrói, é no fundo sua culpa. Eles suportam o mal que fazem, porque eles o justificam pela má essência do outro. Aqueles que refletem, buscando nas ciências humanas aquilo em que fundamentar seus atos, têm a obsessão de fazer o mal. E, em o fazendo, paralisam-se. Paralisam suas ações humanas. Por outro lado, tenho a impressão de que uma criança só cresce se ela encontra ao mesmo tempo a solicitude, mas também alguma coisa de negativo com a qual deve se haver. Tanto no nível dos pais, quanto no dos professores "reflexivos", tenta-se expulsar todo o mal para não estar nunca neste lugar, mas para o outro, este "bom demais", que pode tornar-se mau.

Numa palavra: como, no ideal do profissional pensante, pode-se integrar essa parte que chamarei "negativa", mais do que má? Tenho a impressão de que essa negatividade não se realiza senão no inconsciente, e que então ela pode se verificar destruidora. Existe uma parte de negatividade que é necessária ao encontro humano, e esta parte de negatividade não é "racionalizável", ela é recalcada da idéia do profissional pensante. $\mathrm{E}$ caminha-se na direção de profissionais que têm tanto medo de serem "maus", que não ousam mais arriscar-se no encontro, na confrontação, ao risco de tirar o outro dali onde ele está.

Eu me debato contra uma destrutividade com respeito a um outro, por desconhecimento, por recusa em escutar o que se passa na intersubjetividade (Cifali, 1994). E me escoro numa negatividade que não se pode pensar. Não se pode dizer "sejamos negativos", porque este negativo pode não ser destrutivo, mas construtivo. E como saber se ele é destrutivo ou não? Como pensar em ser "negativo" para que o outro possa sair de si mesmo? Existiria uma negatividade construtiva e uma negatividade destrutiva... Avançar nisso não é intolerável, irresponsável, aventureiro? Imediatamente temo fazer a apologia do inconsciente, da destruição e do irracional. Não é isso, mas é fina a borda na qual a báscula entre o construtivo e o destrutivo se dá. Sinto que tocamos um limite, no entanto, estou persuadida de que não se chega a si mesmo sem ter experimentado esta negatividade. $\mathrm{E}$ claro que existem gestos a se banir definitivamente, como a humilhação, a rejeição, o assujeitamento. Existe uma pacificação que eu quis: levar em conta o outro, não o esmagar com nossa presença ou nossas intenções. E no entanto esta pacificação pode ir até impedir um encontro, em que, enquanto encontro, existe um afrontamento. Tenho dificuldade em exprimir esta contradição. Defendo uma pacificação, uma consciência de nossos atos, e ao mesmo tempo sinto que é preciso restaurar uma cultura do conflito e da negatividade. Esta contradição, como posso tratá-la? Existe também a suspeita de que tomamos freqüentemente uma falsa racionali-

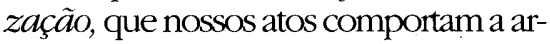
bitrariedade e que nossas decisões não são senão posteriormente racionais, que buscamos sentidos demais.

Toda evolução significa que existe um choque, afrontamento, oposição. Hoje, enquanto profissionais, aceitamos este choque? Evita-se o conflito, faz-se o outro passar primeiro, poderia ser um desvio. Não a cada vez, mas uma tendência, que-é uma intuição - nos convém, pois ocupamos o lugar do bom objeto, mas que deixa o outro sem con- 
frontação. O que aconteceu para que hoje, efetivamente, tenhamos tornado positivos os valores como a escuta, o altruísmo, e tenhamos desertado o afrontamento, o conflito sendo vivido como negativo? Sabemos, no entanto, que nenhum termo é positivo ou negativo, mas operamos sempre essa clivagem.

Não há clivagem entre o bem e o mal, mas uma coisa, um gesto, um ato, uma palavra podem conter um e outro, tornar-se ou um ou outro, segundo o contexto no qual eles se desenrolam. Nada nos põe ao abrigo das conseqüências nefastas que engendram nossos atos, nossas posturas, nossas posições, nossas teorias. A única medida em relação à qual podemos nos guiar nos é dada pelas conseqüências do que fazemos. Não podemos mais ficar na quietude do bom.

Assim, existe algo de negativo no positivo, existe algo de negativo no amor, no respeito. Paul Virilio (1996) nomeia isso "acidente", os acidentes de nossa positividade. Aceitá-lo talvez seja um avanço. Assim, termos como confrontação, violência, conflito, oposição, dependência, frustração, falta nos parecem dever ser expulsos, utilizá-los seria quase de mau gosto. Sofrimento, doença são certamente nossos prêmios, mas que não trazem nada além de sua dor. Não lhes deveríamos nada de nossa humanidade, de nossa evolução, de nossas qualidades. Sabemos que não é assim que acontece. Tornamo-nos friorentos, tomados de uma lógica de segurança. Mas não existe vida sem risco, vida sem morte, não existe si mesmo sem o outro, não existe paz sem confrontação. Não existe vida sem escuta arriscada, como a define Dejours (1993), ou seja, uma escuta na qual corremos riscos também, o de nos encontrar outro, que nossa identidade rache. Correr riscos para si é se deixar afetar pelo outro, e não manter distância, protegido por nosso saber.

Somos convidados a mobilizar os contrários, e não querer expulsar um deles em proveito do outro. A relação com o outro, uma vez que se trata de crescer ou evoluir, não pode ser exemplo de afrontamento, de combate, e de explosão. A partir disso, não podemos nos esquivar nem da escuta, nem do conflito, nem da questão lancinante do "quando somos benéficos, e quando não o somos mais?" Não nos livraremos jamais de tais questões, e felizmente. É preciso navegarmos, renunciando a um instrumento que nos tornaria forçosamente bons, mesmo se ele contiver todas as virtudes humanas. $\mathrm{E}$ aí que me encontro: uma busca de instrumentos, mas que não nos livrem de uma reflexão cotidiana sobre as conseqüências de nossos gestos (Cifali, inédito - a).

\section{RACIONALIDADE}

Seja na medicina ou nas ciências, na filosofia ou na política, a noção de progresso é atualmente interrogada. Na borda do século XXI, vivemos um período no qual duvidamos fortemente que nossos progressos científicos nos ofereçam a perspectiva de dias melhores. A filosofia é convocada, pedese que ela dialogue com os cientistas, para ajudar nas decisões a serem tomadas, diante das opções abertas pelos "progressos da ciência". Fala-se de revolução numérica, de mudança nas relações e na comunicação entre os humanos, de subversão na nossa relação com o tempo e a velocidade. Alguns alertam para transformações psíquicas que isso imporá. Cada impulso de técnica gerou alarmes, com ou sem razão. Interroga-se a ciência, eles denunciam a influência da técnica. Evocam-se as grandes figuras imaginárias 
da ética, como Fausto, Frankenstein e Prometeu (Lecourt, 1996). Teríamos nos tornado tão poderosos no nosso agir e na nossa capacidade de transformar, que poderíamos trazer ao gênero humano tanto a "felicidade", quanto sua destruição.

O que é feito da educação e da transmissão de saberes? Devemos igualmente temer uma racionalidade galopante? Qual é o futuro de nosso progresso? Onde está nossa evolução? A escola está essencialmente em crise: uma queixa corrente. As condições da profissão degradam-se, as crianças mal vêm ao espaço da sala de aula, incapazes às vezes de aprender, de se referenciar, de ser "um entre outros". Uma formidável aposta foi feita: que o saber seja acessivel a todos. Traduzimola em termos de diplomas, e não tanto em termos de gosto ou paixão pelo saber em todos os lugares da vida: reconhecimento para cada um de sua capacidade de ser inteligente nas situações da vida e da profissão. A escola sofre, então, do colégio ao maternal. Mas ela não sofre tanto por causa de um progresso científico, quanto de certas recaídas sociais.

No entanto, o papel da racionalidade na determinação da aprendizagem e do crescer poderia ser a questão de nosso progresso. Alguns desejam que o desenvolvimento das ciências humanas nos dê um controle sobre esses processos que ainda nos escapam. Se controlamos a procriação, por que não chegaríamos a controlar o crescer e o aprender? Estaríamos assim livres de nossas incertezas, evitaríamos sofrimentos psíquicos. Os adultos saberiam como fazer racionalmente. O problema da "educação" seria então resolvido. Em decorrência disso, ser pai, educador ou professor não dependeria senão de uma aplicação de preceitos científicos, maneiras registradas de se por- tar. Nosso sonho de que nossas crianças não tragam mais nenhum problema, nem de crescer, nem de aprender, poderia ser desta forma realizado. Numa tal eventualidade, quem determinará o crescer "direito e conforme", sem sofrimento? Os cientistas, mas em qual verdade descoberta e designada do sujeito? Não sei se se deveria regozijar com um tal sucesso, a diversidade sofrerá, e o poder de uns sobre os outros será diabolicamente reforçado.

O que fazer, contudo, na educação, com essa esperança de que se possa, graças à ciência, ter um agir racionalmente "justo"? Um paralelo poderia ser traçado com os debates atuais em torno da tecnocracia. Tivemos também nossa Hiroxima? Vivemos esse instante em que o conhecimento fundamental ultrapassa o homem e traz a destruição, mesmo se em outro lugar esse mesmo conhecimento desemboca em descobertas que aliviam nossos sofrimentos? Na educação sempre existiu o que causa loucura ou mesmo morte. A ciência poderá ser mais uma loucura, se ela não tomar cuidado, ao lado de outras racionalizações baseadas em delírios mais pessoais. $O$ ato pedagógico e educativo, no entanto, até aqui escapou de uma determinação científica sistemática, e sua aplicação não se transformou em loucura mortífera, como o socialismo científico. Mas o sonho de um controle ronda sempre; para alguns, o espaço da educação ganharia em ser mais cercado de certezas e controlado por uma razão, podemos então ter algumas inquietudes em relação ao futuro.

Apostamos que a racionalidade progredirá certamente, mas nos manteremos sempre na incerteza. Compreendemos talvez que a racionalidade fracassa em governar as almas e as relações intersubjetivas, que ela não pode prever inteiramente o destino humano, 
o sofrimento que advirá, os erros, suas solidões e suas desordens; que não podemos clarear definitivamente essas zonas de sombra; não podemos, e mesmo não o desejaríamos, para salvaguardar a poética do sujeito. O humano no seu devir será sempre entregue à contingência, ao acaso e aos encontros... Em compensação, nos ocorre preservar a inteligência de nossos atos, esta inteligência do momento que no cotidiano realiza uma prática da alteridade e da singularidade. Nossa responsabilidade será a de construir incansavelmente nosso saber e transmiti-lo, num passo clínico (Cifali, inédito - b) que liga uma estética com uma paixão pelo saber, não eliminando nem intuição, nem exigência intelectual.

\section{REFERÊNCIAS BIBLIOGRÁFICAS}

Badiou, A. (1993). L'éthique. Essai surla conscience du mal. Paris: Hatier.

Camus, A. (1994). Le dernier bomme Paris: Gallimard.

Cifali, M. (1994). Lelienéducatif: contre-jour psychanalytique. Paris: PUF.

(1998). Peut-on prévenir la violence? In C. de Tychev (dir. publ.). Psychologie clinique et prévention. Paris: Éditions et Applications Psychologiques. (inédito-a). Clínique et écriture: une influence de la psychanalyse dans les sciences de l'éducation. In Raisons éducative (noprelo).

(inédito-b). "L'altérité en acte", a ser publicado nos atos de um colóquio sobre oacompanhamento, Marselha.

Cifali, M.; Enriquez, E. \& Cornut, J. (1987). Les trois métiers impossibles. Paris: Les Belles Lettres.

Dejours, C. (1993). Trauail, usurementale: essai depsychopathologie du travail. Paris: Bayard.
Eliacheff, C. (1996). Viesprivées. De l'enfant roi à l'enfant victime. Paris: Odile Jacob.

Enriquez, E. (1997). Les jeux du pouvoiret du désir dans l'entreprise. Desclée de Brouwer.

Gadamer, H. G. (1995). L'inaptitude au dialogue. In Langageetzérité. Paris: Gallimard.

Garapon, A. \& Salas, D. (1996). La Républiquepénalisée. Paris: Hachette, p.74.

Gavarini, L. \& Petitot, F. (1998). La fabrique del'enfant maltraité. Toulouse: Erès.

Lagrange, H. (1995). La civilité à l'épreuve, Paris: PUF.

Lecourt, D. (1996). Promethée, Faust, Frankenstein. Fondements imaginaires de l'éthique. Col. Les Empécheurs de Penser en Rond. Synthélabo.

Taylor, C. (1994). Le malaise dela modernité. Paris: Cerf.

Touraine, A. (1997). Pourrons-nous vivre ensemble? Paris: Fayard.

Virilio, P. (1996). Cybermonde, la politiquedu pire. Paris: Textuel.

Winnicott, D. W. (1988). "Cure", conversations ordinaires. Paris: Gallimard, pp.123-33.

\section{NOTAS}

1 Veja M. Gauchet, "La personalité contemporaine et les changements des modes symboliques de socialisation", Travaillerle Social, $\mathrm{n}^{\text {o. }}$ 14, 1995-96.

${ }^{2}$ Veja as obras de F. Imbert e o GRPI, Médiations, institutions et loi dans la classe, ESF, 1994; Linconscient dans la classe, ESF, 1996; Vivre ensemble, ESF, 1997.

${ }^{3} \mathrm{~F}$. Imbert. La question de l'éthique dans le champ éducatif, Vigneux, Matrice, 2e., 1993; F. Imbert et le GRPI, Vivre ensemble, ESF, 1997.

4 "Traiter" la maltraitance: une remise en question, Cabiers Critiques de Thérapie Familialeet de Pratiques de Réseaux, Paris-Butxelas, Universidade De Boeck, 1996. 